Д. Ф. Гончаренко, и.о. ректора, профессор, д.т.н., ХНУСА, г. Харьков

И. А. Менейлюк, докторант, кандидат технических наук, ХНУСА, г. Харьков

\title{
ВЫБОР ТЕХНОЛОГИИ ГИДРОИЗОЛЯЦИИ ПУТЁМ МНОГОКРИТЕРИАЛЬНОГО АНАЛИЗА
}

\begin{abstract}
Аннотация: Статья содержит результаты исследований по выбору наиболее эффективной технологии устройства гидроизолящии с помощью многокритериального анализа. Актуальность исследования подтверждена большим объёмом работ по гидроизоляиии сооружений в странах СНГ, стремительностью создания и развития новых технологий, необходимостью их выбора по множеству критериев сразу. Разработана методика исследования. Основными шагами для многокритериального анализа выбраны: анализ информационных источников по теме; определение технологий для анализа, наиболее значимых критериев эффективности; поиск значений критериев для каждой из рассматриваемых технологий; оценка значимости критериев и выбор наиболее эффективной технологии. Выбраны различные технологии гидроизоляции (монтируемая (бентонитовые маты), напыляемая (жидкая резина), проникающая, обмазочная, оклеечная) $u$ наиболее характерные критерии эффективности (водопоглощение в течении 24 часов; расход на $1 \mathrm{~m}^{2}$; показатель квалификации персонала; морозостойкость; долговечность; стоимость материалов; трудоёмкость на весь объем работ) на основании анализа литературных источников. Каждая из технологий кратко охарактеризована. Оценки по критериям эффективности подтверждены ссылками на информационные источники. Построены таблицы, содержащие значения критериев эффективности соответствующих технологий устройства гидроизоляиионных покрытий в натуральных и балльном измерителях. Приведена диаграмма сравнения технологий. Также определень ранги значимости критериев эффективности путём опроса экспертов. На этом основании рассчитаны интегральные оценки эффективности. Сделан выбор наиболее рациональной гидроизоляционной технологии - монтируемая гидроизолящия из бентонитовых матов. Новизна исследования заключается в разработке и реализации обоснованного подхода к выбору технологии устройства гидроизолячии. Практическая значимость исследования заключается в сборе значений критериев эффективности гидроизоляиионных покрытий различных типов и выборе наиболее рачионального типа.
\end{abstract}

Ключевые слова: многокритериальный анализ, технологии гидроизоляиии, критерии эффективности, стоимость, трудозатраты.

Введение. В настоящее время промышленность продолжает разрабатывать и внедрять новые материалы и технологии, в особенности, гидроизолирующие покрытия. Процессы глобализации и маркетинговая деятельность достигли того уровня, когда такие инновации распространяются стремительно быстро. В этих условиях чрезвычайно важным становится выбор максимально подходящих технологий, их сравнение по наиболее значимым критериям эффективности и последующее определение самой подходящей технологии. Объёмы работ по устройству гидроизоляции в странах СНГ не снижаются, несмотря на сложные экономические условия. При этом отсутствует простая и наглядная методика выбора технологий устройства гидроизоляции по множеству критериев эффективности. Применение такой методики могло бы повысить эксплуатационные качества устраиваемых покрытий, снизить их стоимость. В этой связи задача разработки методики и выбора наиболее эффективной технологии устройства гидроизоляции является актуальной.

Цель и задачи. Целью исследования является многокритериальный анализ и выбор наиболее эффективной технологии устройства гидроизоляции. Для достижения поставленной цели решены следующие задачи:

Разработка методики исследования.

Анализ информационных источников, выбор для рассмотрения технологий устройства гидроизоляции и критериев эффективности.

Составление аналитических таблиц, диаграммы и определение наиболее рациональной технологии.

Методика исследования. В данной работе с помощью многокритериального анализа сравниваются инновационные решения гидроизоляции. Методика показана на рис. $1[6,7]$ :

Результаты многокритериального анализа. В результате первичного анализа информационных источников были выбраны следующие технологии устройства гидроизоляции:

Монтируемая (бентонитовые маты). Бентонитовые маты состоят из гранул бентонитовых глин, расположенных между двумя слоями геотекстиля, соединённых между собой иглопробивным способом $[5,9]$.

Напыляемая (жидкая резина). Жидкая резина это современный гидроизоляционный материал, образующий бесшовную гидроизоляционную мембрану путём взаимодействия битумно-латексной эмульсии и соляного раствора.

Полимеризация жидкой резины происходит уже в воздухе, мгновенно превращая эмульсию в качественную бесшовную мембрану [2].

Проникающая. Представляют собой сухую смесь, состоящую из цемента, кварцевого песка и активирующих добавок. Гидроизоляционный эффект достигается за счёт заполнения пор и микропустот 
Анализ информационных источников, выбор инновационных технологий.

Выбор инновационных решений для сравнения.

Определение критериев эффективности для сравнения.

Количественная и качественная оценка технологий.

Составление аналитических таблиц и диаграмм на основе результатов оценки инноваций.

\section{Анализ диаграмм на основе группирования, сортирования и ранжирования инноваций по различным критериям.}

Рис. 1 Методика выбора технологии устройства гидроизоляции [6, 7]

бетона водонерастворимыми соединениями, образующимися в результате реакции активных химических компонентов с цементным камнем бетона в присутствии воды. Затворённый водой состав наносится на бетон, активные его компоненты вступают в химическую реакцию с цементным камнем, постепенно проникая внутрь структуры бетона и образуя нерастворимые кристаллы. Эти кристаллы закупоривают капилляры и микротрещины, вытесняя при этом воду [4].

Обмазочная - это однослойное или многослойное покрытие толщиной от миллиметра до нескольких сантиметров. Мастичные материалы на органической основе (мастики) - один из самых распространённых видов материалов для создания обмазочной гидроизоляции [3].

Оклеечная - это сплошной водонепроницаемый ковёр из рулонных или гибких листовых материалов, наклеенных в один - четыре слоя на изолируемые горизонтальные, наклонные и вертикальные поверхности специальными мастиками или клеями. Наиболее распространёнными материалами для создания гидроизоляционной мембраны являются рулонные органические материалы [8].

Для принятия оптимального решения по выбору способа устройства кровельного покрытия выбраны следующие критерии эффективности [1, 9 10]:

- водопоглощение в течении 24 часов, \%;

- расход на $1 \mathrm{~m}^{2}$, кг;

- показатель квалификации персонала, в баллах по возрастанию (по результатам экспертной оценки);

- морозостойкость, количество циклов;

- долговечность, лет;

- стоимость материалов на 1 м², у. е.;

- трудоёмкость на 100 м², чел-день.

В качестве базового, для расчёта был выбран объём работ, равный 2686,42 м² гидроизолируемой поверхности.

По выбранным критериям была построена таблица сравнения технологий устройства гидроизоляции (табл. 1). На её основании разработаны аналитическая таблица (табл. 2) и диаграмма (рис. 2), которые построены с помощью инструмента MS Excel "сводные таблицы". Все критерии были сведены к ед-

Таблица 1. Критерии сравнения технологий в натуральных измерителях ([1, 910$])$

Criteria for comparing technologies in natural maesures ([1, 9 10])

\begin{tabular}{|c|c|c|c|c|c|}
\hline Наименование критерия & 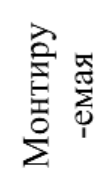 & 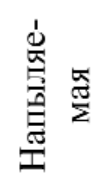 & 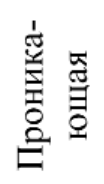 & 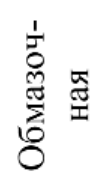 & 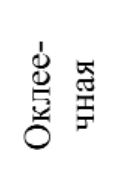 \\
\hline $\begin{array}{c}\text { Водопоглощение в течение } 24 \text { ч., } \\
\%\end{array}$ & 0 & 0,27 & 0,6 & 0,5 & 1 \\
\hline Расход на $1 \mathrm{~m}^{2}$, кг & 5,9 & 2,3 & 1,35 & 0,7 & 4,95 \\
\hline $\begin{array}{c}\text { Показатель требуемой } \\
\text { квалификации персонала, баллы }\end{array}$ & 7 & 8 & 9 & 4 & 5 \\
\hline $\begin{array}{c}\text { Морозостойкость, количество } \\
\text { циклов }\end{array}$ & 200 & 150 & 400 & 20 & 20 \\
\hline Долговечность, лет & 120 & 30 & 110 & 25 & 60 \\
\hline Стоимость материалов на 1 м², у.е. & 9,23 & 19,23 & 13,46 & 7,31 & 3,85 \\
\hline 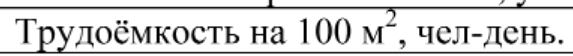 & 37,14 & 4,59 & 10 & 45,93 & 143,28 \\
\hline
\end{tabular}


Таблица 2. "Сводная таблица" многокритериального анализа технологий гидроизоляции "Pivot table" of multi-criteria analysis of waterproofing arrangement technology

\begin{tabular}{|c|c|c|c|c|c|}
\hline Наименование критерия & 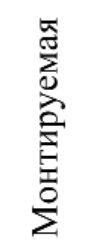 & 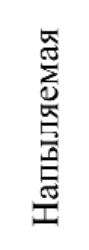 & 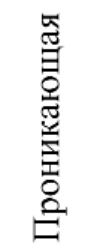 & 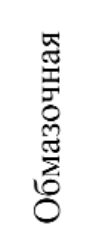 & 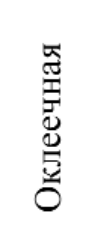 \\
\hline Водопоглощение в течение 24 ч., в баллах по возрастанию & 10 & 7,57 & 1 & 5,5 & 1 \\
\hline Расход на 1 м $^{2}$, в баллах по возрастанию & 1 & 6,19 & 8,88 & 10 & 2,64 \\
\hline $\begin{array}{c}\text { Показатель требуемой квалификации персонала, в баллах } \\
\text { по возрастанию }\end{array}$ & 4,6 & 2,8 & 1 & 10 & 8,2 \\
\hline Морозостойкость, в баллах по убыванию & 5,26 & 4,08 & 10 & 1 & 1 \\
\hline Долговечность, в баллах по убыванию & 10 & 1,47 & 9,05 & 1 & 4,32 \\
\hline 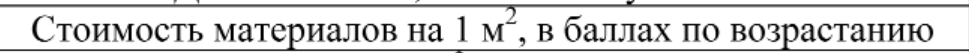 & 6,85 & 1 & 4,38 & 7,98 & 10 \\
\hline Трудоёмкость на 100 м $^{2}$, в баллах по возрастанию & 7,71 & 10 & 9,77 & 7,28 & 1 \\
\hline
\end{tabular}

иной бальной системе. Оценка технологий по количественным критериям производилась по 10-ти бальной шкале, где минимально и максимально эффективным значениям критериев присвоены баллы 1 и 10 соответственно.

Для наиболее корректной оценки были использованы весовые коэффициенты при критериях эффективности. Оценка степени значимости количественных критериев производилась с помощью экспертного опроса. Была составлена опросная анкета (табл. 3). Она заполнена путём очного опроса каждого эксперта отдельно. В ходе опроса не было выявлено новых рассматриваемых технологий, также не были предложены новые критерии оценки. Так как средние арифметические оценок значимости оказались близкими, а повторный опрос не выявил согласованные оценки специалистов, было решено исполь- зовать оценки эксперта 1 как окончательные. После определения степеней значимости критериев были рассчитаны интегральные оценки каждой из рассматриваемых технологий устройства гидроизоляции. Расчёт показан в таблице 4. После расчёта интегральных оценок наибольшее количество баллов получила технология устройства монтируемой гидроизоляции. Её и принимаем в качестве наиболее эффективной.

\section{Выводы:}

1. Представленная методика позволяет делать многокритериальный выбор наиболее эффективной технологии устройства гидроизоляции. Она может использоваться также для других областей.

2. Анализ информационных источников позволил оценить рассмотренные технологии (монтируемая (бентонитовые маты), напыляемая (жидкая резина), проникающая, обмазочная, оклеечная) по

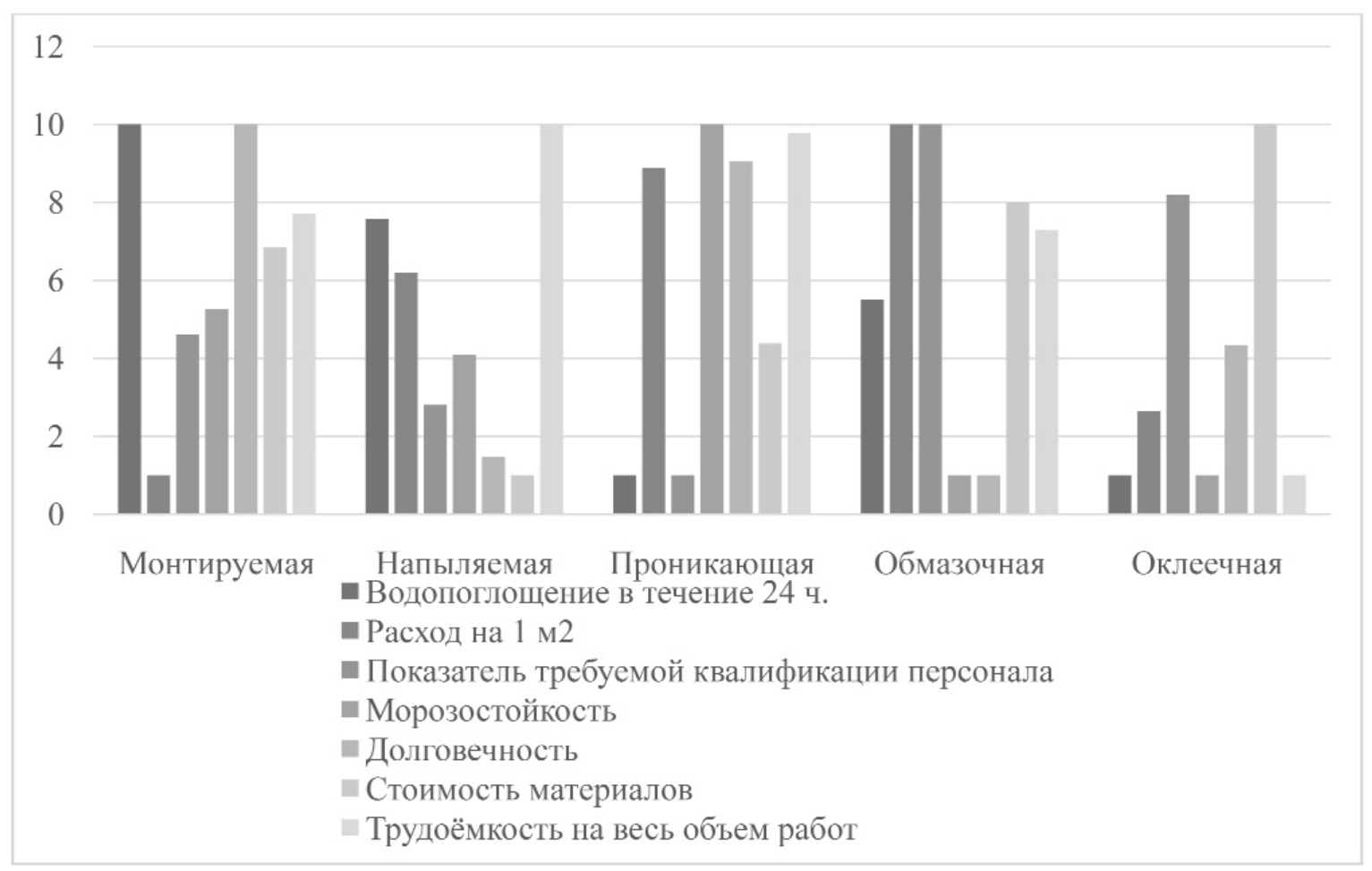

Рис. 2 "Сводная диаграмма" многокритериального анализа технологий устройства гидроизоляции "Pivot diagram" of multi-criteria analysis of waterproofing arrangement technology 
Таблица 3. Опросная анкета, заполненная путём интервьюирования экспертов Questionnaire completed by interviewing experts

\begin{tabular}{|c|c|c|c|c|}
\hline \multirow{2}{*}{$\begin{array}{c}\text { Наименование количественного } \\
\text { критерия }\end{array}$} & \begin{tabular}{c} 
Степени значимости критериев \\
\cline { 2 - 5 }
\end{tabular} & $\begin{array}{c}\text { Оценки } \\
\text { Оценки } \\
\text { эксперта 2 }\end{array}$ & $\begin{array}{c}\text { Оценки } \\
\text { эксперта 3 }\end{array}$ & $\begin{array}{c}\text { Среднее } \\
\text { арифметическое }\end{array}$ \\
\hline Водопоглощение в течение 24 ч. & $\underline{\mathbf{0 , 1 1}}$ & 0,11 & 0,18 & 0,13 \\
\hline Расход на 1 м & $\underline{\mathbf{0 , 1 1}}$ & 0,18 & 0,18 & 0,16 \\
\hline $\begin{array}{c}\text { Показатель требуемой } \\
\text { квалификации персонала }\end{array}$ & $\underline{\mathbf{0 , 1 2}}$ & 0,11 & 0,16 & 0,13 \\
\hline Морозостойкость & $\underline{\mathbf{0 , 1 4}}$ & 0,12 & 0,14 & 0,13 \\
\hline Долговечность & $\underline{\mathbf{0 , 1 6}}$ & 0,18 & 0,11 & 0,15 \\
\hline Стоимость материалов на 1 м & $\underline{\mathbf{0 , 1 8}}$ & 0,14 & 0,12 & 0,15 \\
\hline Трудоёмкость на 100 м & $\underline{\mathbf{0 , 1 8}}$ & 0,16 & 0,11 & 0,15 \\
\hline
\end{tabular}

Таблица 4. Расчёт интегральных оценок технологий устройства гидроизоляции Calculation of integral assessments of waterproofing arrangement technologies

\begin{tabular}{|c|c|c|c|c|c|c|c|c|c|c|c|}
\hline \multirow{3}{*}{$\begin{array}{c}\text { Наименование } \\
\text { количественного } \\
\text { критерия }\end{array}$} & | & \multicolumn{10}{|c|}{ Технологии устройства гидроизоляции } \\
\hline & 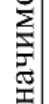 & \multicolumn{2}{|c|}{$\begin{array}{l}\text { Монтиру- } \\
\text { емая }\end{array}$} & \multicolumn{2}{|c|}{$\begin{array}{c}\text { Напыля- } \\
\text { емая }\end{array}$} & \multicolumn{2}{|c|}{$\begin{array}{l}\text { Проника- } \\
\text { ющая }\end{array}$} & \multicolumn{2}{|c|}{$\begin{array}{c}\text { Обмазоч- } \\
\text { ная }\end{array}$} & \multicolumn{2}{|c|}{ Оклеечная } \\
\hline & 离 & 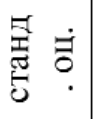 & 家 & 氞 & 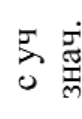 & 袋 & 穴㞼 & 恁 & 方兑 & 茎 & 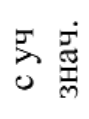 \\
\hline $\begin{array}{c}\text { Водопоглощение } \\
\text { в течение } 24 \text { ч. }\end{array}$ & $=$ & 10 & 1,1 & 7,57 & 0,83 & 1 & 0,11 & 5,5 & 0,61 & 1 & 0,11 \\
\hline Расход на 1 м $^{2}$ & $\overline{8}$ & 1 & 0,11 & 6,19 & 0.68 & 8,88 & 0,98 & 10 & 1,1 & 2,64 & 0,29 \\
\hline $\begin{array}{c}\text { Показатель } \\
\text { квалификации } \\
\text { персонала }\end{array}$ & $\frac{1}{8}$ & 4,6 & 0,55 & 2,8 & 0,34 & 1 & 0,12 & 10 & 1,2 & 8,2 & 0,98 \\
\hline Морозостойкость & $\frac{\pi}{\theta^{\prime}}$ & 5,26 & 0,74 & 4,08 & 0,57 & 10 & 1,4 & 1 & 0,14 & 1 & 0,14 \\
\hline Долговечность & $\frac{0}{2}$ & 10 & 1,6 & 1,47 & 0,24 & 9,05 & 1,45 & 1 & 0,16 & 4,32 & 0,69 \\
\hline $\begin{array}{c}\text { Стоимость } \\
\text { материалов на } \\
1 \mathrm{~m}^{2}\end{array}$ & $\frac{\infty}{8}$ & 6,85 & 1,23 & 1 & 0,18 & 4,38 & 0,79 & 7,98 & 1,44 & 10 & 1,8 \\
\hline $\begin{array}{c}\text { Трудоёмкость на } \\
100 \mathrm{~m}^{2}\end{array}$ & $\frac{\infty}{\infty}$ & 7,71 & 1,39 & 9,77 & 1,76 & 10 & 1,8 & 7,28 & 1,31 & 1 & 0,18 \\
\hline $\begin{array}{c}\text { Интегральная } \\
\text { оценка }\end{array}$ & & & $\underline{6,72}$ & & 4,6 & & 6,65 & & 5,96 & & 4,19 \\
\hline
\end{tabular}

следующим критериям: водопоглощение в течении 24 часов; расход на $1 \mathrm{~m}^{2}$; показатель квалификации персонала; морозостойкость; долговечность; стоимость материалов; трудоёмкость на весь объем работ.
3. Вычисление интегральной оценки эффективности по всем критериям и по трём наиболее значимым из них показало, что наиболее рациональной является технология устройства монтируемой гидроизоляции.

\section{Jumepamypa}

1. ДСТУ Б Д.2.2-...2008 Ресурсні елементні кошторисні норми на будівельні роботи - Київ: Мінрегіонбуд України, 2008. - $35 c$.

2. Авдеева К.В., Юиков Б.С. Гидроизоляция напылением жидкой резины // Журнал: Экологоя и научно-технически прогресс. Урбанистика. - 2013. - Том 2. - С. 17-29.

3. Зарубина Л. П. Гидроизолящия конструкиий, зданий и сооружений. - СПб.: БХВ-Петербург, 2011. - 272 c.

4. Попченко С. Н. Гидроизолячия сооружений и зданий. - Л.: Стройиздат, Ленингр. отд-ние, 1981. - 304 c.

5. Завьялов С. В. Геосинтетика на основе бентонита // Экспозиция Нефть Газ. - 2013 - №2 (34). - C. 59-62. 
6. Менейлюк А. И. Научные основы выбора инноваций: курс лекщий / Менейлюк А. И., Никифоров А. Л. - Одесса: Одесская государственная академия строительства и архитектуры, кафедра технологии строительного производства, 2017. - $152 \mathrm{c}$.

7. Менейлюк А. И. Оптимизация организационно-технологических решений реконструкции высотных инженерных сооружений / Менейлюк А. И., Ершов М. Н., Никифоров А. Л., Менейлюк И. А. - Киев: ТОВ НВП "Інтерсервіс", 2016. $-334 c$.

8. Шилов В.В., Зубцов А.М. Руководство по проектированию и устройству гидроизоляции фундаментов. - М.: Корпоращия ТехноНИКОЛЬ, 2012. - $194 \mathrm{c}$.

9. Шепеляк В.В. Технологическая карта на устройство наружной гидроизоляции монолитных стен подземной части с использованием высокоэффективных бентонитовых изделий. - Киев: ТОВ "СЕТСО- УКРӒ̈НА", 2012. - 79 c.

10. Технологический регламент на выполнение работ по гидроизолящии и антикоррозионной защите монолитных и сборных бетонных и железобетонных конструкций. - 3-е изд., перераб. и доп. М.: СРО "РСПППГ", 2017. - 68 с

\section{References}

1. DSTU B D.2.2 - ...: 2008 Resursni elementni koshtorisni normi na budivel'ni roboti [Resource Element Estimates for Construction Work] - Kyiv: Ministry of Regional Development, Construction and Housing Communal Services of Ukraine, 2008. - $35 \mathrm{p} .(\mathrm{ukr}$.

2. Avdeeva K.V., Jushkov B.S. Gidroizoljacija napyleniem zhidkoj reziny [Waterproofing by spraying liquid rubber]. Jekologoja i nauchno-tehnicheski progress. Urbanistika, 2013, No 2, 17-29 p.

3. Zarubina L. P. Gidroizoljacija konstrukcij, zdanij i sooruzhenij [Waterproofing of structures, buildings and structures]. SanktPetersburg., BHV-Peterburg, 2011, 272 p.

4. Popchenko S. N. Gidroizoljacija sooruzhenij i zdanij [Waterproofing of buildings and structures]. Leningrad, Strojizdat, 1981, $304 p$

5. Zav 'jalov S. V. Geosintetika na osnove bentonita [Bentonite-based geosynthetics]. Jekspozicija Neft' Gaz, 2013, №2 (34), pp. 59-62.

6. Menelyuk A.I., Nikiforov A.L. Nauchnye osnovy vybora innovacij: kurs lekcij [Scientific fundamentals of the choice of innovations: course of lectures]. Odessa, Odessa State Academy of Construction and Architecture, Department of Technology for Construction Production, 2017, 152 p. (rus.)

7. Menelyuk A.I., Ershov M.N., Nikiforov A.L., Menelyuk I.A. Optimizacija organizacionno-tehnologicheskih reshenij rekonstrukcii vysotnyh inzhenernyh sooruzhenij [Optimization of organizational and technological solutions for the reconstruction of high-rise engineering structures]. Kiev, Scientific-production enterprise "Interservis" LLC, 2016, 334 p. (rus.)

8. Shilov V.V., Zubcov A.M. Rukovodstvo po proektirovaniju i ustrojstou gidroizoljacii fundamentov [Guidelines for the design and installation of waterproofing foundations]. Moskow, Korporacija TehnoNIKOL, 2012, 194 p.

9. Shepeljak V.V. Tehnologicheskaja karta na ustrojstvo naruzhnoj gidroizoljacii monolitnyh sten podzemnoj chasti s ispol'zovaniem vysokojeffektivnyh bentonitovyh izdelij [Technological guidelines for external waterproofing of the monolithic walls of the underground part using high-performance bentonite products]. Kiev, TOV "SETSO- UKRAÏNA", 2012, 79 p.

10. Tehnologicheskij reglament na vypolnenie rabot po gidroizoljacii i antikorrozionnoj zashhite monolitnyh $i$ sbormyh betonnyh $i$ zhelezobetonnyh konstrukcij [Technological regulation for waterproofing and anticorrosive protection of monolithic and precast concrete and reinforced concrete structures]. Moskow, SRO "RSPPPG", 2017, 68 p.

Д.Ф. Гончаренко, в.о. ректора, професор, д. т. н., ХНУБА, м. Харків

I. О. Менейлюк, докторант, к. т. н., ХНУБА, м. Харків

\section{ВИБІР ТЕХНОЛОГІЇ ГИДРОІЗОЛЯЦИИ ШЛЯХОМ БАГАТОКРИТЕРІАЛЬНОГО АНАЛІЗУ}

Анотація. Стаття містить результати досліджень з вибору найбільш ефективної технологї влаштування гідроізолящї за допомогою багатокритеріального аналізу. Актуальність дослідження підтверджена великим обсягом робіт з гідроізолячї споруд в країнах СНД, стрімкістю створення і розвитку нових технологій, необхідністю їх вибору по безлічі критеріӥв відразу. Розроблено методику дослідження. Основними кроками для багатокритеріального аналізу обрані: аналіз інформаційних джерел по темі; визначення технологій для аналізу, найбільш значущих критерїв ефективності; пошук значень критерїв для кожної з розглянутих технологій; оцінка значимості критерїв $і$ вибір найбільш ефективної технологї. Обрані різні технологї гідроізолячії (вмонтовується (бентонітові мати), напилювана (рідка гума), проникаюча, обмазочна, обклеювальна) і найбільш характерні критерії ефективності (водопоглинання протягом 24 годин; витрата на 1м2; показник кваліфікащї персоналу; морозостійкість; довговічність; вартість матеріалів; трудомісткість на весь обсяг робіт) на підставі аналізу літературних джерел. Кожна з технологій коротко охарактеризована. Оцінки за критеріями ефективності підтверджені посиланнями на інформащійні джерела. Побудовано таблиці, що містять значення критеріӥв ефективності відповідних технологій пристрою гідроізолячійних покриттів в натуральних $і$ бальному вимірі. Наведено діаграма порівняння технологій. Також визначено ранги значущості критерїв ефективності шляхом опитування експертів. На иій підставі розраховані інтегральні оцінки ефективності. Зроблено вибір найбільш раціональної гідроізоля- 
ційної технологї - вмонтовується гідроізолящія з бентонітових матів. Новизна дослідження полягає в розробці та реалізації обгрунтованого підходу до вибору технологї влаштування гідроізолячї. Практична значимість дослідження полягає в зборі значень критеріїв ефективності гідроізолячійних покриттів різних типів і виборі найбільш раціонального типу.

Ключові слова. багатокритерійний аналіз, технологї гідроізоляиї, критерї ефективності, вартість, трудовитрати.

D.F. Honcharenko, rector, Full Professor, Doctor of Engineering Sciences

Kharkiv National University of Civil Engineering and Architecture,

61000, Ukraine, Kharkiv, Sumska st., 40

I.O. Menejljuk, Doctoral student, Candidate of Engineering Sciences

Kharkiv National University of Civil Engineering and Architecture,

61000, Ukraine, Kharkiv, Sumska st., 40

\section{WATERPROOFING TECHNOLOGY CHOICE BY MULTI-CRITERIA ANALYSIS}

Abstract. The article contains the results of the choice of the most effective waterproofing arrangement technology using multi-criteria analysis. The relevance of the study was confirmed by the large amount of waterproofing work in the CIS countries, the rapid development of new technologies, their selection need according to many criteria at once. A research methodology has been developed. The main steps for multi-criteria analysis are selected: analysis of information sources on the topic; identification of technologies for analysis, the most significant effectiveness criteria; search for criteria values for each of the considered technologies; assessment of the criteria significance and selection of the most efficient technology. There were chosen different waterproofing arrangement technologies (mounted waterproofing (bentonite mats), sprayed waterproofing (liquid rubber), penetrating waterproofing, painting waterproofing, pasting waterproofing) and the most important effectiveness criteria (water absorption within 24 hours; consumption per 1m2; staff qualification; frost resistance; durability; cost of materials; the labor complexity of the entire scope of work) based on the analysis of informational sources. Each of the technologies was briefly characterized. Evaluations by performance criteria were confirmed by references to information sources. The tables were constructed containing the values of the effectiveness criteria of the relevant waterproofing technology, in natural and scoring gauges. The technology comparison chart was shown. There were also identified significance ranks of the effectiveness criteria by experts interviewing. On this basis, integrated performance evaluations were calculated. The choice of the most rational waterproofing technology was made - mounted waterproofing by bentonite mats. The novelty of the research lies in the development and implementation of a reasonable approach to the choice of waterproofing technology. The practical significance of the study is to collect the values of the effectiveness criteria of various types of waterproofing and choose the most rational one.

Keywords. multi-criteria analysis, waterproofing technology, effectiveness criteria, cost, labor spent. 